\title{
Effect of Solid Solution + Double Ageing on Microstructure and Properties in the Layer by Layer of the Z-Y Interface of Inconel 718 alloys Fabricated by SLM
}

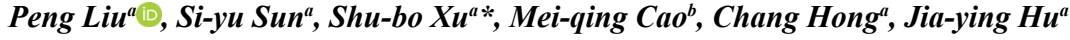 \\ ${ }^{a}$ School of Materials Science and Engineering, Shandong Jianzhu University, Jinan 250101, P. R.China \\ ${ }^{b}$ School of Materials Science and Engineering, Shandong University of Science and Technology, \\ Qingdao266590, P. R. China
}

Received: June 04, 2018; Revised: August 16, 2018; Accepted: September 05, 2018

\begin{abstract}
The microstructure in the Z-Y surface of Inconel 718 alloys fabricated by selective laser melting (SLM) shows the relatively homogeneous and irregular fine grain structure after the heat treatment process of $1050^{\circ} \mathrm{C}$ solid solution + double ageing. A large number of bulk precipitates were observed on the grain boundary, and the typical dendritic crystallization and Laves phases disappeared. It is possible that a large number of $\delta$ phases $\left(\mathrm{NbNi}_{3}\right)$ were precipitated on the grain boundary since the enrichment effect of element $\mathrm{Nb}$. The hardness in the Z-Y surface increased from $350 \mathrm{HV}$ to $500 \mathrm{HV}$, and the residual stress was transformed from the tensile stress to compressive stress.
\end{abstract}

Keywords: selective laser melting, Ni-based alloys, heat treatment, microstructure, residual stress.

\section{Introduction}

Inconel 718, a Ni-based superalloy, has the ability of retaining mechanical stability at a high temperature $\left(650^{\circ} \mathrm{C}\right)$, excellent resistant to oxidation, high temperature corrosion, creep resistance and good fatigue life ${ }^{1-3}$. Hence, it is widely used in aircraft turbines, jet engines and steam turbine power plants ${ }^{4}$. However, the present cast components have coarse grain size, dendritic segregation and some solidification defects, which lead to poor mechanical properties of Inconel 718 alloy. In addition, it is difficult to control the performance of this alloy and produce complex geometries for the special wrought form ${ }^{5}$. With the characters that can produce more homogeneous and finer microstructures, Selective laser melting (SLM) consequently could be a prospective candidate to replace conventional production processes ${ }^{6}$. This process can offer several advantages, such as like reduction of production steps, high flexibility, low material consumption and, the most importantly, the possibility to manufacture parts with high geometrical complexity and dimensional accuracy.

However, since the complexity of the non-equilibrium SLM process, some problems, such as residual stresses, porosity, directional grain growth, segregation, creation of non-equilibrium phases, and other process induced defects have to be systematically considered and studied. In order to achieve the desired mechanical and microstructural properties, post heat treatment was commonly required for relieving residual stresses and for facilitating the precipitates of strengthening phases ${ }^{7,8}$. Feng et al. ${ }^{9}$ reported that a process of $1050^{\circ} \mathrm{C}$ solid solution + double ageing was used. After the heat treatment, the microstructure on the upper surface showed the homogeneous bulk crystal structure. The typical columnar crystals and dendrites also disappeared. The

*e-mail: xsb200606@126.com growth of grain that showed relatively fine structure was limited. However, it is well known that the Inconel 718 alloy fabricated by SLM was built by a method of layer by layer ${ }^{10}$. Therefore, the microstructure, properties and residual stress near the layer by layer interface during the heat treatment will also experience the vitally important change, which has an obvious effect on the reconstruction of microstructure and properties for Inconel 718 alloy fabricated by SLM.

In this paper, Inconel 718 alloy fabricated by SLM were heat treated using a suitable $1050{ }^{\circ} \mathrm{C}$ solid solution + double ageing to observe the changes in microstructure, phase constituents, hardness and residual stress near the layer by layer interface. This study will provide a reference for the further research of heat treatment and reconstruction of Inconel 718 alloys fabricated by SLM.

\section{Experimental Techniques}

In our research, Inconel $718 \mathrm{Ni-based} \mathrm{alloy} \mathrm{of} \mathrm{was}$ produced by SLM. The chemical composition (At.\%) of Inconel 718 alloys fabricated by SLM is $0.41 \% \mathrm{Al}, 0.84 \% \mathrm{Ti}$, $18.11 \% \mathrm{Cr}, 18.30 \% \mathrm{Fe}, 49.42 \% \mathrm{Ni}, 5.48 \% \mathrm{Nb}, 3.05 \% \mathrm{Mo}$ and $4.39 \%$ other. Inconel 718 spherical powder is used during the process of SLM, and the power size is $45 \sim 65 \mu \mathrm{m}$. The SLM equipment used is $500 \mathrm{Yb}$-fibre laser of FS421M type (Farsoon Technologies, China), the wavelength is $1050 \mathrm{~nm}$. The scanning speed is $0 \sim 15 \mathrm{~m} / \mathrm{s}$, and the spot diameter is $60 \sim 200 \mu \mathrm{m}$. The laser power selected in this experiment was $350 \mathrm{~W}$, and the scanning speed was $700 \mathrm{~mm} / \mathrm{s}$. In addition, the Ar gas was used as the protective gas in the melting process.

Inconel 718 alloys fabricated by SLM were made into a series of samples with dimensions $10 \mathrm{~mm} \times 10 \mathrm{~mm} \times 10 \mathrm{~mm}$ through a lining cutting machine. Then, a suitable heat treatment processes of $1050^{\circ} \mathrm{C}$ solid solution + double 
ageing were adopted, and the detailed process was holding $1 \mathrm{~h}$ at $1050^{\circ} \mathrm{C}$, air cooling to $720^{\circ} \mathrm{C}$, holding $3 \mathrm{~h}$ at $720^{\circ} \mathrm{C}$, air cooling to $620^{\circ} \mathrm{C}$, holding $3 \mathrm{~h}$ at $620^{\circ} \mathrm{C}$, air cooling to room temperature. And then, the microstructural analysis, microhardness test and scanning electron microscopy (SEM) in the Z-Y surface (see Fig. 1a and 1b) of Inconel 718 alloy fabricated by SLM were performed before and after the heat treatment. Residual stresses in the depth direction were measured based on incremental hole drilling method (Prism residual stress measurement system). A blind, flat bottomed hole was drilled on the surface of the Inconel 718 alloy (see Fig. 1c). The variations of surface strain, due to the relaxation of the surrounding material, were then recorded and calculated into residual stresses. The residual stresses in depth from 0 to $0.5 \mathrm{~mm}$ were measured. Each measurement was repeated for 3 times, and the average value was selected as the experimental value. A ratio of eroding solution, $5 \mathrm{~g}$ $\mathrm{CuCl}_{2}+100 \mathrm{ml} \mathrm{HCl}+100 \mathrm{ml} \mathrm{CH}_{3} \mathrm{CH}_{2} \mathrm{OH}$, was used for the microstructural analysis. The test equipments used are as follow: Horizontal metallurgical microscope of Nikon Epiphot 300U/200 and SEM equipment of JSM-6380LA.

\section{Results and Discussion}

\subsection{Microstructures}

Fig. 2 shows that the microstructure of the Z-Y surface before and after heat treatment processes for Inconel 718 Ni-based alloy. According to Fig. 2a, the obvious welding layer structure can be observed in the Z-Y surface without heat treatment process. This reason was mainly due to the deposition of metal between welding layers in the process of SLM. The obvious and large interlayered structure existed is favorable to induce the intermetallic compounds formed easily. Moreover, the microstructure shows the seriously inhomogeneous in the Z-Y surface with lots of melting tracks formed by SLM (see Fig. 2a). However, after the heat treatment process, the microstructure of alloys shows the relatively homogeneous and irregular fine grain structure (see Fig. 2b). It is obvious that the solid solution + double ageing process have the important effect on the whole microstructural properties increased. As a result, the microstructural transformation in the Z-Y surface will play an important role.

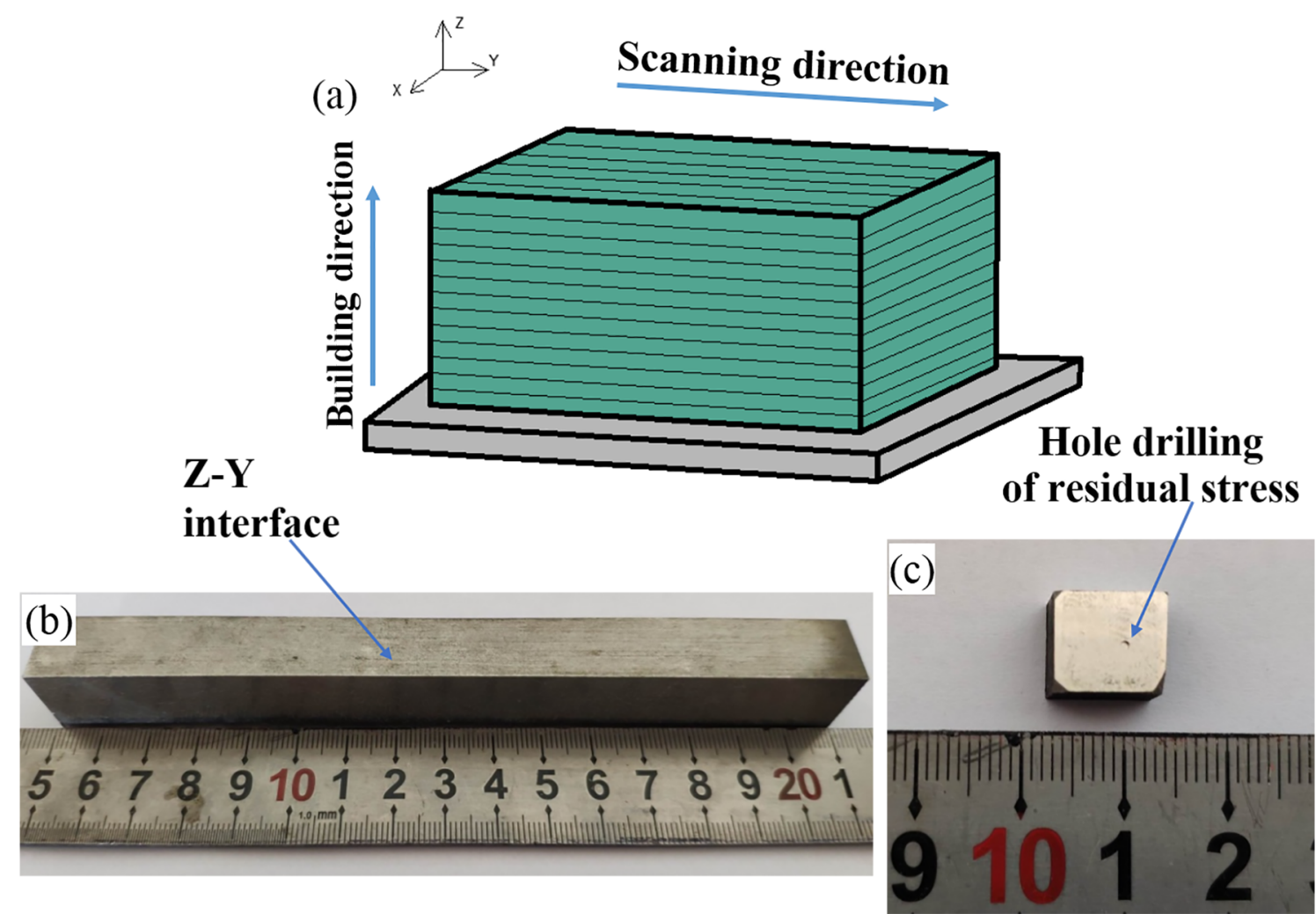

Figure 1. The schematic of Inconel 718 Ni-based alloys fabricated by SLM. (a) The building schematic of alloys; (b) The image of the components produced; (c) The image of hole drilling of residual stress measured. 



Figure 2. Microstructure in the Z-Y surface of Inconel-718 Ni-based alloys. (a) Microstructure of unheated; (b) Microstructure after heat treatment.

In order to further know the influence of heat treatment process on the microstructural transformation in the Z-Y surface of Inconel-718 Ni-based alloys, SEM with energy dispersive spectrometer was used to observe and analyze the alloys. Fig. 3 shows the microstructure of alloys by SEM. The EDS analysis results of typical precipitates in the Z-Y surface of alloys are shown in Table. 1.

It is well known that the basic phase of Inconel 718 Ni-based alloys is $\gamma$ structure, and elements $\mathrm{Cr}, \mathrm{Al}$ and Mo should be dissolved in $\gamma$ phase ${ }^{11}$. According to Fig. 3a, the structure shows the typical dendritic crystallization character. The dendritic crystallization was composed of solid solution of $\gamma$ phase $^{12}$. Moreover, it can be found that some small precipitates, Laves phase $\left((\mathrm{Ni}, \mathrm{Fe}, \mathrm{Cr})_{2}(\mathrm{Nb}\right.$, Mo, Ti)), existed among these dendritic crystallizations ${ }^{13}$. However, when the solid solution + double ageing process were used, the microstructure experienced an obvious change (see Fig. 3b). A large number of bulk precipitates were observed on the grain boundary, and the typical dendritic crystallization and Laves phases disappeared.

The chemical composition among dendrites crystallization in the Z-Y surface for the unheated alloys is shown in Table 1 (point A). This is according to SEM analysis. Therefore, there should be Laves phase in the grain, and these phases were the intermetallic compounds of typical brittleness ${ }^{13}$. The chemical composition of point $\mathrm{B}$ can also be seen in Table 1 . The EDS results indicated that the content of element $\mathrm{Nb}$ increased obviously from $4.18 \%$ to $34.01 \%$. Moreover, the content of $\mathrm{Cr}$ and $\mathrm{Ni}$ decreased obviously, and element $\mathrm{Mo}$ disappeared. That is to say, the content of these elements related to formation of Laves phases decreased. Therefore, when the heat treatment was performed, Laves phases could be dissolved. At this time, since the enrichment of element $\mathrm{Nb}$, it is possible that a large number of $\delta$ phases $\left(\mathrm{NbNi}_{3}\right)$ of solution were further promoted to precipitate on the grain boundary ${ }^{13}$. In addition, with the increase of the content of element $\mathrm{C}$, it is possible that there were also some carbide (such as $\mathrm{Cr}-\mathrm{Ni}-\mathrm{Fe}-\mathrm{C})^{8}$.

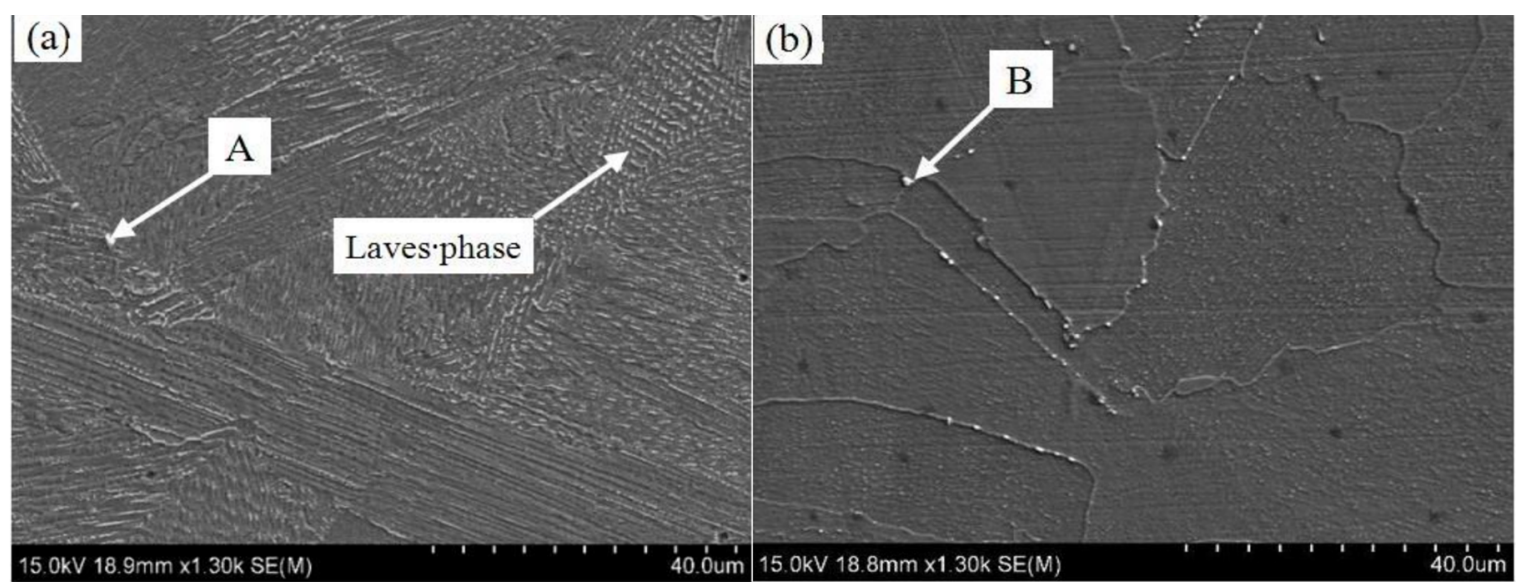

Figure 3. SEM morphology of Inconel-718 Ni-based alloys before and after heat treatment. (a) Morphology of precipitates of unheated; (b) Morphology of precipitates of heat treatment. 
Table 1. The EDS analysis of precipitates in the Z-Y surface of alloys (wt. \%).

\begin{tabular}{|c|c|c|c|c|c|c|c|c|}
\hline \multirow{2}{*}{ Location } & \multicolumn{8}{|c|}{ Element } \\
\hline & $\mathrm{C}$ & $\mathrm{Al}$ & Mo & $\mathrm{Ti}$ & $\mathrm{Cr}$ & $\mathrm{Fe}$ & $\mathrm{Ni}$ & $\mathrm{Nb}$ \\
\hline A & 2.45 & 0.76 & 3.35 & 0.86 & 18.64 & 18.44 & 51.32 & 4.18 \\
\hline B & 5.48 & 2.11 & 0.00 & 3.72 & 8.07 & 14.35 & 32.26 & 34.01 \\
\hline
\end{tabular}

\subsection{Microhardness and residual stress}

According to the above analysis, the microstructure of alloys has the obvious changes. Therefore, it is possible to reflect the relation between microstructure change and heat treatment process through analyzing the hardness distribution of alloys. Vickers hardness tests were conducted using Vickers indenter with a $200 \mathrm{~g}$ loading and a load time of $10 \mathrm{~s}$. The hardness distribution in the Z-Y of alloys before and after heat treatment is shown in Fig. 4.

The test results indicated that there was an obvious change of hardness in the Z-Y surface for Inconel 718 alloys fabricated by SLM after heat treatment. It is clear that the hardness increased from $350 \mathrm{HV}$ to $500 \mathrm{HV}$. Although Laves phases that are typical hard and brittle intermetallic compound could be dissolved after heat treatment by means of SEM analysis, the obvious fine grain structures and a larger number of $\delta$ phases precipitated on the grain boundary will be important factor to enhance the hardness in the Z-Y surface of alloys. In addition, with the increase of the content of element $\mathrm{C}$, some carbide ( $\mathrm{Cr}-\mathrm{Ni}-\mathrm{Fe}-\mathrm{C})$ existed is also possible reason for the increase of hardness. Simultaneously, with the solution of Laves phases at the high temperature, the segregation of element $\mathrm{Nb}$ generated, which formed the $\delta$ phases. The existence of $\delta$ phases will enhance the thermal stability at the high temperature of Inconel 718 alloys, and increase the ability of impact resistance and high temperature resistance ${ }^{14}$.

Fig. 5 shows the distribution of residual stress in the Z-Y surface in the direction of depth of alloys before and after heat treatment. The test result indicated that the residual stress was transformed from the tensile stress to compressive stress, which will have an important effect on the obvious increase of hardness in the Z-Y surface of alloys $^{15}$. Moreover, the grain refinement, solution of Laves phases and formation of $\delta$ phases could be vital effect on the change of residual stress.

\section{Conclusions}

In conclusion, the microstructure on the Z-Y surface of alloys shows the relatively homogeneous and irregular fine grain structure after the heat treatment process. A large number of bulk precipitates were observed on the grain boundary, and the typical dendritic crystallization and Laves phases disappeared when the solid solution + double ageing process were used. It is possible that a large number of $\delta$ phases $\left(\mathrm{NbNi}_{3}\right)$ of solution were further promoted to precipitate on the grain boundary since the enrichment of element $\mathrm{Nb}$.

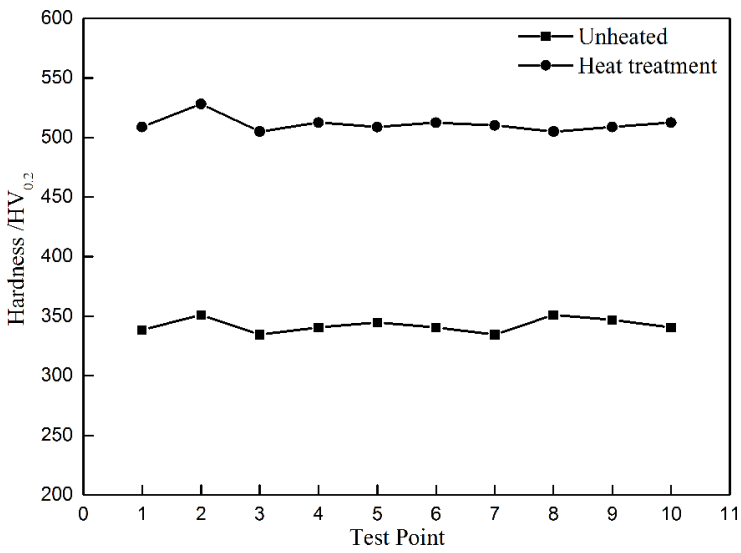

Figure 4. The curve of hardness distribution in the Z-Y surface of alloys before and after heat treatment.

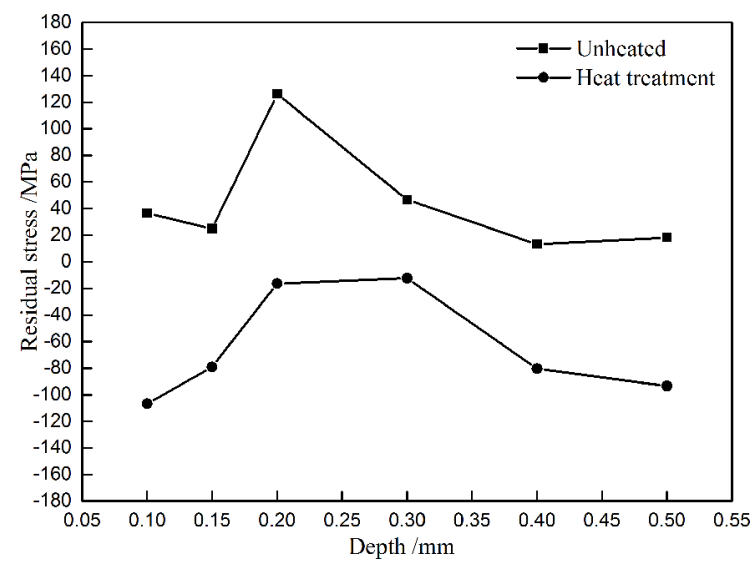

Figure 5. The distribution curve of residual stress in the Z-Y surface in the direction of depth of alloys before and after heat treatment.

In addition, the hardness on the Z-Y surface increased from $350 \mathrm{HV}$ to $500 \mathrm{HV}$, and the residual stress was transformed from the tensile stress to compressive stress. Therefore, the grain refinement, solution of Laves phases and formation of $\delta$ phases could be vital effect on the change of hardness and residual stress.

\section{Acknowledgments}

This research was financially supported through the Shandong Provincial Natural Science Foundation, China (Grant No. ZR2016JL017) and the Key Research Development Program of Shandong Province, China (Grant No. 2017GGX30128). 


\section{References}

1. Zhao R, Li XJ, Wan M, Han JQ, Meng B, Cai ZY. Fracture behavior of Inconel 718 sheet in thermal-aided deformation considering grain size effect and strain rate influence. Materials \& Design. 2017;15:413-425.

2. Qi H, Azer M, Ritter A. Studies of Standard Heat Treatment Effects on Microstructure and Mechanical Properties of Laser Net Shape Manufactured INCONEL 718. Metallurgical and Materials Transactions A. 2009;40(10):2410-2422.

3. Wang JT, Zhang DH, Wu BH, Luo M. Residual Stresses Analysis in Ball end Milling of Nickel-Based Superalloy Inconel 718. Materials Research. 2017;20(6):1681-1689.

4. Chamanfar A, Sarrat L, Jahazi M, Asadi M, Weck A, Koul AK. Microstructural characteristics of forged and heat treated Inconel-718 disks. Materials \& Design (1980-2015). 2013;52:791-800.

5. Sufiiarov VS, Popovich AA, Borisov EV, Polozov IA. Selective laser melting of heat-resistant Ni-based alloy. Non-Ferrous Metals. 2015;1(38):32-35.

6. Kunze K, Etter T, Grässlin J, Shklover V. Texture, anisotropy in microstructure and mechanical properties of IN738LC alloy processed by selective laser melting (SLM). Materials Science and Engineering: A. 2015;620:213-222.

7. Zhang YC, Li ZG, Nie PL, Wu YX. Effects of Heat Treatment on Niobium Segregation of Laser-Cladded IN718 Alloy Coating. Metallurgical and Materials Transactions A. 2013;44(2):708-716.

8. Amato KN, Gaytan SM, Murr LE, Martinez E, Shindo PW, Hernandez J, et al. Microstructures and mechanical behavior of Inconel 718 fabricated by selective laser melting. Acta Materialia. 2012;60(5):2229-2239.
9. Feng KY, Liu P, Li HX, Sun SY, Xu SB, Li JN. Microstructure and phase transformation on the surface of Inconel 718 alloys fabricated by SLM under $1050^{\circ} \mathrm{C}$ solid solution + double ageing. Vacuum. 2017;145:112-115.

10. He BB, Wu WW, Liang L, Lu L, Yang QY, Long QL, et al. Microstructural characteristic and mechanical property of Ti6Al4V alloy fabricated by selective laser melting. Vacuum. 2018;150:79-83.

11. Wang ZN, Li J, Fang QH, Liu B, Zhang LC. Investigation into nanoscratching mechanical response of $\mathrm{AlCrCuFeNi}$ high-entropy alloys using atomic simulations. Applied Surface Science. 2017;416:470-481.

12. Li RB, Yao M, Liu WC, He XC. Isolation and determination for $\mathrm{d}, \gamma^{\prime}$ and $\gamma^{\prime \prime}$ phases in Inconel 718 alloy. Scripta Materialia. 2002;46(9):635-638.

13. Xiao H, Li SM, Xiao WJ, Li YQ, Cha LM, Mazumder J, et al. Effects of laser modes on Nb segregation and Laves phase formation during laser additive manufacturing of nickel-based superalloy. Materials Letters. 2017;188:260262.

14. Liu WC, Yao M, Chen ZL. Effect of cold rolling on the precipitation behavior of d-phase in Inconel 718. Metallurgical and Materials Transactions A. 1999;30(1):31-40.

15. Kattoura M, Mannava SR, Qian D, Vasudevan VK. Effect of ultrasonic nanocrystal surface modification on elevated temperature residual stress, microstructure, and fatigue behavior of ATI 718Plus alloy. International Journal of Fatigue. 2018;110:186-196. 